\title{
A RELACIÓN ENTRE LA CASA ROGER DE FIGUERES Y LAS PINTURAS DE SALVADOR DALÍ REALIZADAS EN 1929
}

\author{
MARC BORRÁS ESPINOSA
}

Universitat de Barcelona

marcborrases@gmail.com

\begin{abstract}
Resumen: La presencia de una gran langosta en ciertas pinturas de Salvador Dalí se ha explicado iconológicamente como fruto de su fobia. El origen de este insecto se sitúa en el subconsciente del pintor, siendo anticipo del método paranoico-crítico. Sin embargo, un estudio de los edificios de la calle Monturiol, donde vivió su niñez y juventud, desvela un origen concreto de este ortóptero, revelando el uso consciente de los elementos presentes en sus pinturas.
\end{abstract}

Palabras clave: Salvador Dalí / El Gran Masturbador / Langosta / Fuente / 1929.

Abstract: The presence of a big grasshoppers in certain Salvador Dali's paintings has been explained iconologically as the result of his phobia. The origin of this insect is located in the painter's subconscious, being an advance of his paranoid-critical method. However, a study of the buildings on Monturiol Street, where he lived his childhood and youth, unreil a particular origin of this orthopteran, revealing the conscious use of the elements present in his paintings.

Key words: Salvador Dalí / The Great Masturbator / grasshopper / Source / 1929.

Durante el año 1929 Salvador Dalí introdujo en varios de sus cuadros una gran langosta, siendo casi un arquetipo compulsivo, despareciendo prácticamente este insecto de su imaginario una vez concluido este año. ${ }^{1}$

Su significado iconológico parece un hecho resulto: sería un símbolo del terror insuperable cuyo origen iconográfico devendría de su fobia por este insecto, la cual Dalí describió en su Vida secreta: ${ }^{2}$ según explica el artista, de niño le encantaban las langostas, hasta que un día cogió un pez viscoso en la playa en cuyo rostro descubrió la efigie de un ortóptero. A partir de este momento, nació en él una fobia que jamás superó, siendo motivo de bromas y suplicios por parte de sus compañeros de escuela, los cuales disfrutaban lanzándole langostas o aplastándolas dentro de sus libros. ${ }^{3}$

Sin embargo, a pesar de que la magnificencia, lo inabarcable y el terror son elementos habituales en su obra, este insecto aparece con insistencia durante un periodo muy concreto de su vida creativa, desapareciendo de sus pinturas después de instalarse en París, repudiado por su familia. Además, este insecto es representado siempre dimensionado y normalmente en solitario, y tan solo en El Gran Masturbador (1929, Museo Nacional Centro de Arte Reina Sofía, Madrid) se representa de forma que podamos relacionarlo directamente

\footnotetext{
* Fecha de recepción: 15 de abril de 2017 / Fecha de aceptación: 10 de julio de 2017.

1 La obra de Salvador Dalí resulta demasiado extensa como para lanzar una sentencia absolutista, pero sí puedo manifestar que desconozco la existencia de ninguna pintura que presente una langosta con posterioridad a 1929 con excepción de La fuente (1930, The Salvador Dalí Museum, St. Petersburgo [Florida]) y Primer retrato de Gala (1931, Albert Field Collection, New York). La primera pintura cuenta con 3 langostas en vez de una como ocurre en casi todas las pinturas de 1929, pero repite los elementos comunes de las pinturas de 1929 que presentan este insecto. Por lo que hace a la segunda obra, conviene remarcar el carácter personal de la pintura, además de que también repite varios elementos de las pinturas de 1929.

2 DALí, Salvador, 1981, pp. 135-138.

${ }^{3}$ El texto más antiguo en el que Salvador Dalí se refiere a las acciones de sus compañeros data de 15 de octubre de 1920, cuando tenía 16 años, relatando en su diario privado que Al matí els companys m'empipen amb lo de la "Ilagosta". DALí, Salvador, 1994, p. 139.
} 
con su infancia, pues en esta obra aparece con un hilo atado a una pata. ${ }^{4}$

Dalí, cuando quiso, fue muy específico en su Vida secreta, como cuando explica que su fobia le hacía ver langostas incluso donde no las había ${ }^{5}$ o al hacer referencia a lugares concretos de Figueres, tales como el Castillo de San Fernando, la Font Trobada, el colegio de las Hermanas de la Doctrina Cristiana, el colegio de las Hermanas Maristas o la casa que le vio nacer: el núme- ro 20 de la calle Monturiol, actualmente número 6.

Por el contrario, cuando quiso fue muy parco en detalles y se gustó de las inexactitudes, ${ }^{6}$ como ocurre con la ubicación de su segundo taller. ${ }^{7}$ Dalí explicó extensamente cómo lo instaló en la parte alta de la casa de sus padres, en el lavadero, e incluso explica como varias de las creaciones que realizó allí fueron anticipo de lo que con posterioridad crearía en París a partir de $1929,{ }^{8}$ pero en ${ }^{4}$ Aquestes llagostes espantoses de Figueres, mig esclafades al caire de les voravies, arrossegant un llarg fil brut lligat a les ca-
mes i sotmeses al martiri lent i ferotge dels jocs que els nens els infligien [...]. DALÍ, Salvador, 1994, p. 137 .
${ }^{5}$ Al col-legi, la meva por de les llagostes va arribar a ocupar tot l'espai de la meva imaginació. Les veia pertot arreu, fins i tot
on no n'hi havia: un paper grisós, vist de cop $i$ volta, i que em semblava una llagosta, em feia llançar un udol que encisava
tothom; una simple molla de pa o una bola de goma que em llancessin de darrere estant i em toqués el cap em feia saltar
amb tots dos peus sobre el pupitre, tremolant, mirant el meu voltant, angoixat mortalment per la por de descobrir l'insecte
horrible, sempre a punt de saltar. DALí, Salvador, 1994, p. 137. Esta fobia es confirmada, junto a otras, por su hermana: Las ta-
quillas, el teléfono y los saltamontes son coses que siempre le han causado terror. DALí, Ana María, 2001, p. 73. Salvador Dalí la relata de nuevo en: DALí, Salvador; PARIANUD, André, 1975, pp. 53-55.

${ }^{6}$ Su hermana, Ana María Dalí, manifestó que su hermano daba una visión desfigurada de su niñez y juventud en su autobiografía: "Cuando escribí el libro Salvador Dalí visto por su hermana, no me proponía otra cosa que dar a conocer el ambiente de nuestra casa durante los primeros veintiséis años de la vida de mi hermano. Habían quedado tan desfigurados en su libro Vida secreta, que no se correspondían, en absoluto, con la realidad". DALÍ, Ana María, 2001, p. 19. Fèlix Fanés, por su parte, hace hincapié en como Dalí en varias ocasiones parece remarcar ciertos aspectos creativos e influencias para ocultar otros, tratando así de ocultar sus verdaderas fuentes visuales de inspiración. Véase: FANÉS, Fèlix, 2004, p. 101

7 Hasta 1921, su taller se encontraba en la en la calle Llaner, muy cerca de su casa, en un inmueble propiedad de Ramonet Pichot. Véase: DALÍ, Ana María, 2001, p. 25.

${ }^{8}$ La meva mare va estar un quant temps preguntant-me: "Preciós, què desitges? Preciós, què vols?". Jo ja sabia què volia. Volia una de les habitacions del safreig, situades al terrat de casa, les quals, com que ja no les feien servir, feien només de dipòsit. I un dia la vaig obtenir $i$ em va permetre d'usar-la com a cambra d'estudi. Van pujar les minyones a treure tots els fòtils $i$ traslladar-los a un galliner que hi havia allí a la vora. I l'endemà vaig entrar en possessió de la petita peça del safreig, que era tan reduïda que el safreig de coment ocupava gairebé tot l'espai, tret de l'espai, tret de l'estricament restringides del meu primer estudi corresponien a aquelles reminiscències de plaers intrauterins que ja he descrit en els meus records d'aquest període.

"Em vaig instal.lar, doncs, de la manera següent: vaig col/locar la meva cadira a l'interior del safreig, i la fusta que servia perquè la bugadera no es mullés el vestit, de manera que la tapava a mitges. Aquesta era la meva taula de treball. De vegades, en dies molt calorosos, em despullava. I aleshores només havia d'obrir l'aixeta, i l'aigua amb què s'omplia el safreig em, pujava cos amunt fins cintura. Aquesta aigua, provinent d'un depòsit en el qual tocava el sol tot el dia, era tèbia. Era un cosa semblant al bany de Marat. L'espai buit entre el safreig i les parets era distinta a la col/lecció dels objectes més variats, $i$ les portes eren cobertes de pintures fetes damunt unes capes de barrets, d'una fusta molt flexible, que robava a la casa de modes de la meva tia Caterina. Les dues pintures a l'oli que vaig fer assegut al safreig foren les següents: una representava l'escena de I'"encontre de Josep amb les seves germanes" $i$ era tot imaginària; la segona era, fins a cert punt, plagiada d'una il/lustració d'un llibret de colors que era una adaptació de la llíada i mostrava Helena de Troia, de perfil, mirant cap a l'horitzó. La Ilegenda deia: "I el cor dormit d'Helena es va omplir de records..." En aquesta pintura (que jo somiava molt), gairebé a l'extrem de l'horitzó, vaig pintar una torre altíssima amb una figureta al cim. Era indubtablement jo mateix! A més de les pintures, hi havia objectes que a eren embrions d'aquells objectes surrealistes inventats més tard, el 1929, a París. També vaig fer en aquesta època una còpia de la Venus de Milo en fang; vaig treure d'aquest meu primer esforç escultòric un plaer eròtic inequívoc i deliciós. Havia pujat al meu safreig tota la meva colllecció d'art "Govens"; aquestes petites monografies, que el meu pare m'havia regalat tan prematurament, produïren en mi un efecte que fou un dels més decisius en la meva vida. Vaig arribar a saber-me de memòria totes aquelles pintures de la història de l'art, que m'han estat familiars de de la meva primera infantesa, car em passava dies sencers contemplant-les. M'atreien principalment els nus, i l'Edat d'or d'Ingres em semblava la pintura més bonica del món, i em vaig enamorar de la nena nua que simbolitza la font.

"Fóra inacabable la reació de tot el que vaig experimentar en el meu safreig; però hi ha una cosa ben certa: que hi van néixer els primers grans de sal i pebre del meu humor. Vaig començar a posar-me a prova $i$ a observar-me, acompanyant les meves picades d'ullet voluptuoses amb un lleu somriure maliciós, mentre advertia vagament, confusament, que jugava a ésser un geni. Oh, Salvador Dalí! Ara ho saps! Jugant a ésser un geni s'arriba a ser-ho!

"Els meus pares no es cansaven de respondre a la invariable pregunta que els seus amics els feien en el curs d'una visita: "I en Salvador?". "En Salvador és al terrat. Diu que ha instal.lat el seu taller de pintura al safreig. S'hi passa tot sol hores i hores". "Allà dalt!". Vet aquí la frase meravellosa! Tota la meva vida ha estat determinada per aquestes dues idees antagòniques, el cim $i$ el fons. Des de la meva primera infantesa em vaig esforçar desesperadaments per ésser al "cim". Hi he arribar, $i$ ara que hi sóc, m'hi quedaré fins la mort. DALí, Salvador, 1981, pp. 74-76. 
ningún momento menciona el que la familia se había trasladado a un nuevo hogar, la Casa Mas Roger, en el número 24 de la calle Monturiol, actual número 10, ubicada a apenas diez metros de su casa natal. ${ }^{9}$ Resulta difícil sostener que se trata de un descuido, pues Dalí en su Vida secreta hace una alusión velada al cambio de hogar, al afirmar que un niño nació en la calle Monturiol presa del amor infinito de sus padres y que a su muerte no sería así. ${ }^{10}$ Lo más probable es que se trate de una omisión premeditada y no un descuido.

Sin abandonar la casa que le vio nacer, existe una omisión consciente de Dalí que llama aún más la atención y que probablemente tenga una relación directa con varias pinturas de 1929: la fachada de la Casa Roger, en el actual número 9 de la calle Monturiol. Esta vivienda se encuentra a apenas 15 metros de su casa natal y a poco más de $\mathbf{4 0}$ metros de la Casa Mas Roger, y se ubica en la acera de enfrente de las dos viviendas en las que residió Dalí junto a sus padres. Se trata de un edificio propio de la arquitectura ecléctica bien resuelto con elementos modernistas, la típica arquitectura burguesa catalana de finales del siglo XIX. Su arquitecto fue Josep Azemar Pont, data de 1888 y en ella existe una simbiosis de elementos clásicos y góticos, sobresaliendo del conjunto dos elementos: las gárgolas simuladas que representan una rana y una langosta. Nos interesa la segunda, puesto que resulta llamativo que Dalí, el cual padecía de una fobia por este ortóptero y que además se jactó de encontrarlos durante su niñez incluso donde no los había, no menciona en ninguno de sus textos autobiográficos la presencia de una langosta de un metro ubicada enfrente de su casa natal.

Dalí describió en su Vida secreta las visitas a sus vecinos y las tardes que pasó en su comedor, ${ }^{11}$ que en el caso de estar ubicado dando a la calle (como es habitual en España),12 quedaría a la misma altura que la langosta, del mismo modo que se vería perfectamente desde el tejado de la Casa Mas

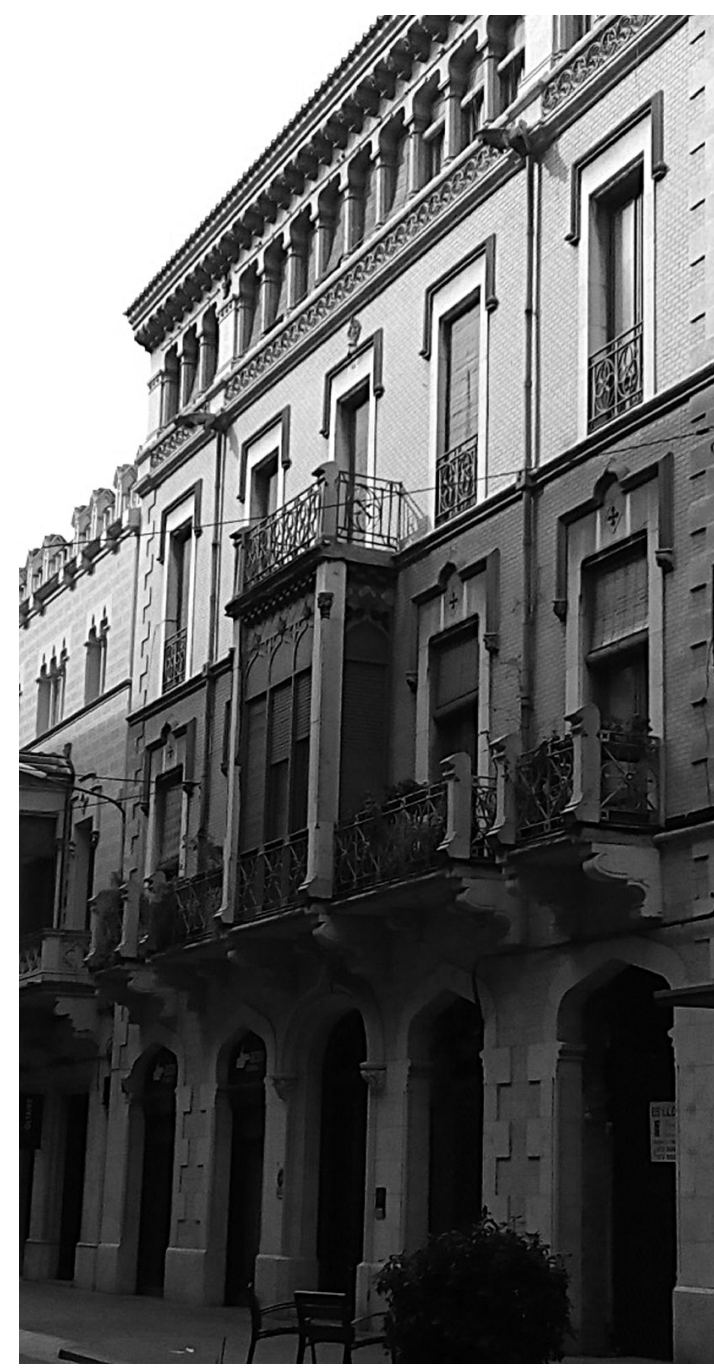

Fig. 1. Casa Roger. Calle Monturiol, $\mathrm{n}^{\circ}$ 9. Josep Azemar Pont. 1888. Figueres.

Roger donde realizó varios cuadros en los que aparece este insecto. ${ }^{13}$ Su hermana, a su vez, explica como el lugar favorito de la familia en su primer hogar era la galería, la cual daba a la calle Monturiol y el desaparecido jardín de la marquesa de la Torre. ${ }^{14}$ Pero lo más importante: resulta casi

\footnotetext{
${ }^{9}$ Su hermana sí mencionó este episodio: "Inmediatamente se decidió cambiar de casa, y como justamente en la misma calle [Monturiol], formando esquina con la plaza de la Palmera y la calle Caamaño, se estaba construyendo una muy grande, incluso lujosa para aquel tiempo, a ella decidimos trasladarnos". DALí, Ana María, 2001, p. 40. Menciona de nuevo el traslado en DALÍ, Ana María, 2001, p. 49.

10 En una casa del carrer Monturiol un nounat és observat atentament $i$ amb amor infinit pels seus pares i provoca un lleu desordre domèstic acostumant. Infeliços de vosaltres! Recordeu bé el que ara us diré: no serà així el dia que moriré! DALí, Salvador, 1981, p. 36.

11 DALí, Salvador, 1981, p. 5.

12 A su vez, su hermana confirma que desde su casa se veía la calle Monturiol: "A uno y otro lado, la casa daba a las dos calles más céntricas de Figueres. La fachada principal a la calle Monturiol; la otra, a la de Caamaño". DALÍ, Ana María, 2001, p. 32.

13 I had my work. I locked myself in Figueres Studio for a Month. I finished The Great Masturbator and Portrait of Paul Élard. DALÍ, Salvador; PARINAUD, André, 1976, p. 90.

14 DALí, Ana María, 2001, p. 32.
} 


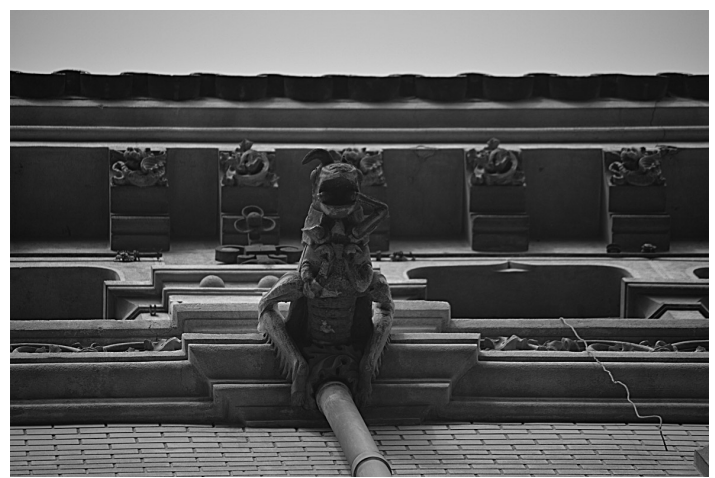

Fig. 2. La langosta de la Casa Rogers. Josep Azemar Pont. 1888. Figueres. Fotografía de Celia Arjona.

imposible el creer que Dalí pasó 26 años de su vida sin percatarse que frente a su casa existía una escultura de un metro que representa el animal que es motivo de uno de sus miedos más irracionales. ¿Resulta plausible que el ojo del Dalí niño, adolescente y joven, $\tan$ vivo e imaginativo a lo largo de su vida, pasara por alto este detalle? Resulta una idea difícil de sostener. Además, la Casa Roger, la Casa Mas Roger y la casa natal de Dalí, conocida como Casa Puig, repito, todas ellas ubicadas en la misma calle, son obra del mismo arquitecto: Josep Azemar Pont, por no decir que su taller daba directamente a la calle Monturiol. ${ }^{15}$ Son demasiados elementos comunes como para pensar que Salvador Dalí jamás se hubiera percatado de la presencia del descomunal insecto, que de pequeño le encantaba y que a partir de un trauma se convierte en fuente de sus pesadillas, se encontraba frente a su casa. No cabe duda de que Dalí omitió su presencia, incluso cuando describe la vista desde el tejado de su casa: Dalí describe la bahía de Roses y el cementerio, ${ }^{16}$ pero no menciona su calle, de forma claramente consciente.

A pesar de ello, no debemos pensar que esta escultura le causara un terror especial. El pintor no mencionó nunca que la representación de una langosta le asustara, de manera que tenemos que pensar que esta escultura, a nivel fóbico, le resultaba indiferente. Este hecho lo prueba el que dicho animal aparezca en varios de sus cuadros, el que colgase

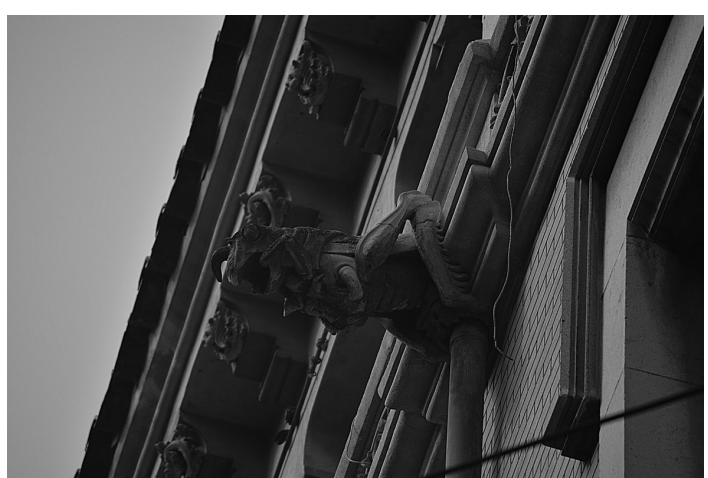

Fig. 3. La langosta de la Casa Rogers. Josep Azemar Pont. 1888. Figueres. Fotografía de Celia Arjona.

en su apartamento parisino El Gran Masturbador en los años treinta y el que aparezca este ortóptero sin ningún valor negativo en su poema $\mathrm{El} \mathrm{Campo}{ }^{17}$ (1927-1929, Fondo Dalí del Museo Abelló, Mollet del Valles [Barcelona]). Sin embargo, la omisión de la existencia de la escultura resulta indicativo de que Dalí no deseaba hablar de ella.

Hablemos ahora de las pinturas. En 1929 Dalí, tras conocer a Picasso, Paul Eluard y realizar junto a Buñuel Un Chien Andalu, regresa a Figueres y Cadaqués, poblaciones separadas por tan solo 33 $\mathrm{km}$, y comienza a recordar su periodo infantil. Según el pintor, ${ }^{18}$ venían a su cabeza imágenes imprecisas que no podía situar ni en un lugar ni momento concretos, pero que estaba seguro las había visto en su niñez. Afirma que entre estas imágenes se encontraban algunas más complejas y condensadas, describiendo el perfil de la cabeza de un conejo, el ojo del cual era también el ojo de un loro que a su vez servía de cabeza de un pez envuelto en otros dos y que en ocasiones sobre la boca de este pez aparecía una langosta, lo cual casa en buena medida con lo mostrado en las pinturas de 1929. Afirma que se dedicó a plasmar estas visiones escrupulosamente en una pintura, $E I$ juego lúgubre (1929, Colección particular), sin seguir su gusto ni criterio, haciendo caso únicamente a los dictados de su proximidad y unión sentimental, creando una de las obras más auténticas atribuible a la razón surrealista.

15 "Las dos espaciosas habitaciones que forman el taller de mi hermano en Figueres dan a la calle Monturiol". DALÍ, Ana María, 2001, p. 84.

16 DALí, Salvador, 1981, p. 76.

17 Hi ha un aglà lluent / El grill, la sorra, el blat de moro / la llagosta; són un núvol. / Les herbetes, el cargol, l'aglà; són el cel. IEl pits de la pagesa, les seves mans i la punta dels dits / son l'aigua de la riera. Texto de Salvador Dalí en: MINGOT BATLLOR, Joan M. (ed.), 2001, p. 68. También aparece la langosta ("I'énorme sauterelle", en el francés original) como elemento poético en el poema El Gran Masturbador: DALÍ, Salvador, 2008.

18 DALí, Salvador, 1981, pp. 231-232. 
Ese año le visitó en Cadaqués su marchante Camille Goemans, a quien le muestra su cuadro, aún inacabado, El juego lúgubre, primera obra en la que aparece una langosta sobre la boca de un gran rostro, siendo el insecto mayor que los personajes que aparecen en el cuadro, presentando este rostro humanoide inmerso en sí la cabeza de un ave. Es conocido lo que continuó después: la llegada a Cadaqués del poeta Paul Eluard ${ }^{19}$ con la que era su esposa, Gala, el fulminante enamoramiento de Dalí y el alejamiento, largo pero temporal, de Dalí y su padre tras la exposición en París del dibujo Sagrado Corazón, donde podía leerse "A veces escupo por gusto sobre el retrato de mi madre".

Pero volvamos por el momento a El juego lúgubre. Según Dalí, es fruto de una imaginación liberada e inconsciente, pero algunos elementos, por más que descontextualizados, poseen un referente claro, como ocurre con el león con una zarpa sobre una bola, el cual tiene su fuente sin duda alguna en los leones que custodian la entrada del Congreso de los Diputados de Madrid. ${ }^{20}$ Así mismo, las caracolas marinas y las piedras son iguales a las que se encuentran por las rocas de Cadaqués, el cáliz con la hostia consagrada es un elemento eucarístico representado en la misma disposición en cientos de cuadros españoles, etc. Así mismo, varios autores han apuntado la relación entre el Jardín de las Delicias del Bosco (15001505, Museo Nacional del Prado, Madrid) y El Gran Masturbador ${ }^{21}$ y obras similares, entre las que podemos englobar El juego lúgubre: la formación rocosa antropomorfa de la tabla del Paraíso del famoso tríptico del Bosco parece servir de inspiración para el rostro blando pero rocoso (que se ha asociado también con la roca Cullaró de Cap de (reus $^{22}$ ) sobre el que descansa la langosta.

A pesar de las explicaciones creativas que dio Dalí, y a pesar de que las uniones de cabezas de humanos, peces y aves casan con lo que él mismo dijo,

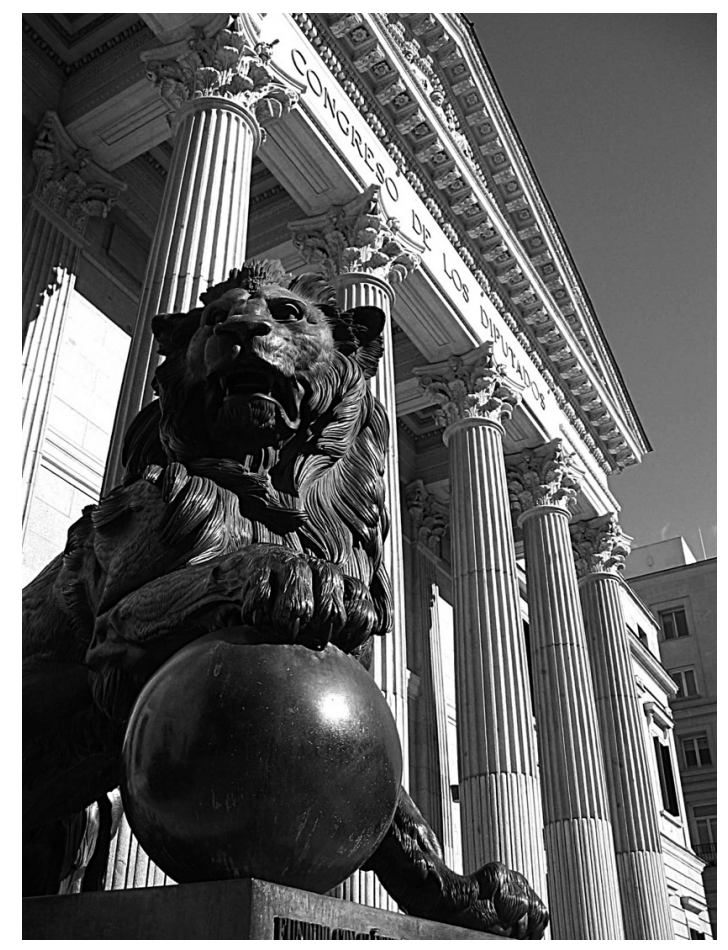

Fig. 4. León derecho del Congreso de los Diputados. Ponciano Ponzano. 1865. Madrid.

parece claro que la ejecución de esta pintura no fue totalmente subconsciente, sino que unió elementos por él conocidos tal y como haría el subconsciente. Esto parece claro debido a la gran cantidad de recursos visuales por él conocidos que empleó en este tipo de pinturas. En el caso concreto del El juego lúgubre hacen referencia a sus años en Madrid (Congreso de los Diputados, El Bosco), a su día a día en Cadaqués (conchas, erizos de mar, red de pescador, un barco en cuya lona hay una G [¿Girona?]. La abyección sexual presente en los calzones con excrementos parecen una lectura bizarra de Freud y es clara la influencia de

\footnotetext{
19 Fue justamente Paul Eluard quien bautizó esta pintura con el nombre de El juego macabro. Véase: DALÍ, Salvador, 1981, p. 243.

${ }^{20} \mathrm{En}$ El juego lúgubre aparecen dos leones de color y brillo metálico, alusión difícilmente discutible del Congreso de los Diputados.

${ }^{21}$ FALKENBURG, Reindert. The Land of Unlikeness. Hieronymus Bosch, The Garden of Earthly Delights. Wbooks, 2011, pp. 124-125. YARZA LUACES, Joaquín. El Bosco y la pintura flamenca del siglo XV. Madrid: TF Editores, 2010, p. 50. Citados en: VÁZQUEZ DUEÑAS, Elena, 2016, pp. 113-114. FANÉS, Fèlix, 2000, pp. 54-61. La hermana de Salvador Dalí explicó el gran interés que tenía su hermano por el pintor tras su expulsión de la Real Academia de Bellas Artes de San Fernando: "Tenía un gran empeño en que visitemos el Museo del Louvre y los de Bélgica, pues Salvador tiene gran interés por ver las obras del Bosco, Brueghel y especialmente las de Vermeer de Delft, a quien toda la vida ha admirado". DALÍ, Ana María, 2001, p. 114. Más adelante relata: "Salvador zumba furiosamente en el taller. Su trabajo es intenso. Está creando cuadros de pura fantasía y, al mismo tiempo de un gran realismo, que recuerdan a los de Brueghel y Bosco". DALÍ, Ana María, 2001, p. 124.

22 FANÉS, Fèlix, 2000, p. 56.
} 


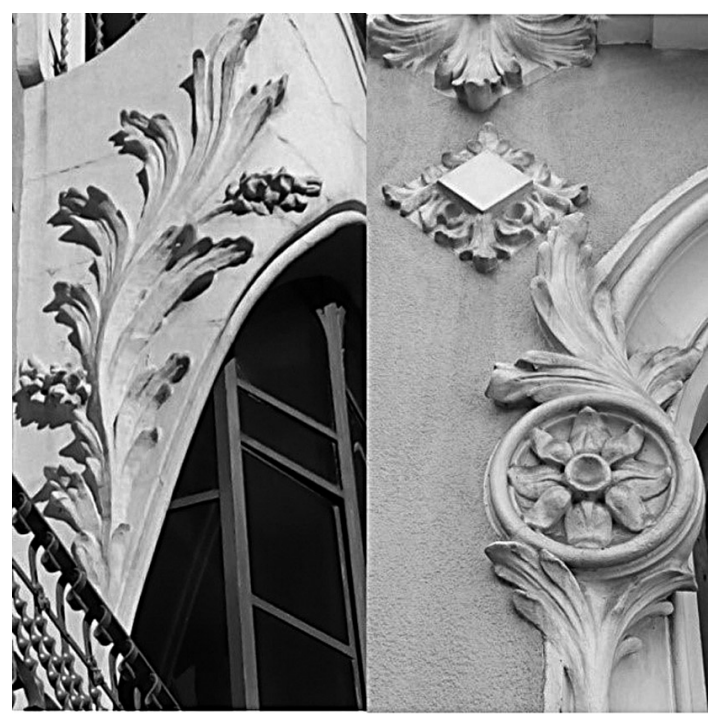

Fig. 5. Detalles de ornamentos arquitectónicos. Casa Jiménez. Plaza de la Palmera, no 1. Josep Bori Gensana. Hacia 1907. Figueres.

Giorgio de Chirico, que el mismo Dalí se encargó de negar o minimizar. ${ }^{23}$ Este empeño por negar y ocultar referencias e influencias explícitas resulta lógico, pues esta pintura era la que le convertía, según el propio Dalí, en el verdadero y absoluto pintor surrealista según los postulados de Bretón. ${ }^{24}$ En cualquier caso, tanto si esta pintura es fruto del absoluto subconsciente como pretende Dalí o si son pinturas que simulan al subconsciente, algo queda claro: está formada por elementos que devienen de la experiencia concreta de Dalí, tanto de sus recuerdos como de su día a día a caballo entre Figueres y Cadaqués, así que al igual que los elementos talásicos tienen una relación directa con Cadaqués, el empleo de una gran langosta puede (y casi debe) tener relación con la gran langosta que señorea en su calle, siendo además el que omita su existencia indicio de su relación directa. ${ }^{25}$

Poco después de que Gala partiese dirección París desde la estación de Figueres, Dalí se encerró un mes en su estudio en la casa paterna concluyendo una de sus obras más renombradas, la cual la describe así: "Representaba una gran cabeza, amarilla como la cera, muy rojizas las mejillas, largas pestañas i con una nariz imponente comprimida contra el suelo. Este rostro no tenía boca, y en el lugar de la boca había enganchada una langosta enorme. El vientre de la langosta se descomponía y estaba llena de hormigas. Algunas de estas hormigas corrían a través del espacio que debería haber llenado la boca inexistente de la gran cara angustiada, la cabeza de la cual acababa en una arquitectura y ornamentación estilo 1900. El título de la pintura era El Gran Masturbador". ${ }^{26}$ Esta descripción de la pintura resulta muy reveladora, pues a pesar del presumible empeño de Dalí por enmascarar la influencia que en él ejerció la Casa Roger, deja traslucir dos elementos que la relacionan: el primero es que no se trata de una langosta sobre un rostro, sino que se trata de una "langosta enorme" sobre un rostro, como enorme es, respecto al insecto real, la gárgola del edificio. Segundo, que en la obra se encuentra "una arquitectura y ornamentación estilo 1900", coincidiendo con el estilo de la Casa Roger, visible desde el hogar paterno. Sin embargo, resulta innegable que la ornamentación de la Casa Roger es historicista, tratando de simular la arquitectura gótica y clásica. Sin embargo, existe otro edificio ubicado frente a la vivienda de Dalí, cuyas ornamentaciones son mucho más parecidas a este detalle repetido en diversas pinturas de 1929: la Casa Jiménez, en el actual número 1 de la plaza de la Palmera, que continúa con la calle Monturiol, que si bien no presenta un relación de original/copia en las pinturas de Dalí, bien pudo servirle de fuente de inspiración, pues coinciden en su carácter botáni$\mathrm{Co}^{27}$

La casualidad, por más que posible, parece mucha, además de que esta coexistencia entre el ornamento modernista y la langosta es común en las pinturas de 1929, entre las que se encuentran, además de las ya mencionadas: El enigma del deseo - mi madre, mi madre, mi madre (1929, Staatsgalerie Modern Kunst, Munich), Profanación

\footnotetext{
${ }^{23}$ Era també el contrari de la pintura de Chirico, car aquí l'espectador a de creure obligadament en la realitat terrenal del tema, que és de caràcter elemental i frenèticament biològic. DALí, Salvador, 1981, p. 232.

24 Jo, doncs, i només jo, era el veritable pintor surrealista, almenys segons la definició que el seu capdavanter, André Breton, donava del surrealisme. DALÍ, Salvador, 1981, p. 232.

${ }^{25}$ Los viajes a Figueres durante 1929 resultan obvios, no solo por ser donde se encontraba la residencia familiar, sino porque el propio Dalí afirma haber realizado obras allí. Véase la nota 13.

26 Traducción del autor a partir de: DALí, Salvador, 1981, p. 262.

27 Fèlix Fanés, por su parte, hace alusión a la relación entre las formas modernistas y un espejo del mismo que formaría parte del mobiliario de la casa paterna. Véase: FANÉS, Fèlix, 2004, p. 95.
} 
del anfitrión / La profanación de la hostia 28 (1929, The Salvador Dali Museum, St. Petersburg [Florida]), Retrato de Paul Éluard (1929, Colección particular), Los placeres iluminados ${ }^{29}$ (1929, MoMA, New York) y Los primeros días de la primavera ${ }^{30}$ (1929, The Salvador Dalí Museum, St. Petersburg [Florida]).

Varios elementos de estas pinturas poseen un cariz local o reconocible en la vida de Dalí: las rocas, conchas y erizos marinos de Cadaqués, una presencia masculina alejada, clara alusión al distanciamiento con su padre, las parejas que se abrazan que se pueden relacionar con Gala y Dalí o las hormigas, que además, en el caso de El Gran Masturbador, surgen del vientre de la langosta, iconografía fácilmente vinculable al episodio por él relatado en su Vida secreta, en el apartado Falsos recuerdos de infancia, cuando creyó ver una masa de hormigas surgiendo de las nalgas de un niño. ${ }^{31}$ También, como ya he mencionado, algunos aspectos parecen poseer un origen iconográfico en sus años de estudiante en Madrid. Una vez desgranados todos estos aspectos, habiéndose probado cómo la iconografía de Dalí tiene un origen concreto e inmediato en él, resulta más que factible el que su calle le sirviese también de inspiración iconográfica, más si cabe aun que Cadaqués o Madrid, sobre todo a razón de que desde su taller, donde realizó varias de estas pinturas, veía directamente la calle Monturiol con la gran langosta de la Casa Rogers y la plaza de la Palmera con la Casa Jiménez y su ornamentación estilo 1900.

Un elemento que nos ayuda a remarcar el carácter personal de las fuentes iconográficas de estas obras, locales además muchas de ellas, es el poema que Dalí escribió en septiembre de 1930 en Port-Lligat: El Gran Masturbador..$^{32}$ El título ya nos avisa del paralelismo con la obra homónima, y su lectura nos la confirma. A pesar de su cariz surrealista, la obra se desarrolla en un espacio claramente identificable con el plano ampurdanés que se extiende desde Cadaqués hasta las ruinas griegas y romanas de Ampurias, ${ }^{33}$ en la localidad de l'Escala. Ya al comenzar el poema, se habla del ruido de la ciudad y cómo entre los transeúntes se encontraban campesinos pululando por la carretera que unía la humilde aldea de Hunt y la orgullosa Kistern. Se trata de una alusión clara a los pueblecitos y aldeas cercanas a la ciudad de Figueres y la ciudad misma, siendo la calle Monturiol que le vio nacer una de las arterias que unían los campos y la Rambla, uno de los centros neurálgicos de la ciudad. ${ }^{34}$ Menciona seguidamente otra carretera humilde cuyos campos están preparados para ser abonados, describiendo así el paisaje de las afueras de la ciudad visibles desde la azotea del hogar paterno. Describe a continuación al Gran Masturbador con su nariz sobre el suelo, encontrándose en la membrana que cubre enteramente su boca un enorme saltamontes (la langosta), agarrado inmóvil y pegado contra ella cinco días y cinco noches. Este énfasis en la inmovilidad del insecto remarca la idea de que su fuente iconográfica sea la gárgola de la Casa Roger, y desvincula su significado con el terror insuperable, pues, tal y como Dalí dice a lo largo de sus textos autobiográficos, su pánico residía en verla saltar, en encontrarla muerta en sus libros de colegio... pero en cualquier caso, su reacción ante el animal era huir de él; si la obra posee un carácter autobiográfico o propio del subconsciente, como siempre se ha dicho, esta inmovilidad del insecto sobre el Gran Masturbador, así como su actitud estática, no concuerdan con la fobia. Dalí nos da una pista acerca de este punto. La presencia de la langosta no transmite

\footnotetext{
28 Esta es la única pintura de 1929 que presenta más de una langosta, mostrando un total de cuatro.

29 Esta pintura no presenta ninguna ornamentación de inspiración modernista.

30 Tampoco esta pintura presenta ninguna ornamentación de inspiración modernista.

31 Ja en aquest període recordava una escena que, d'improbable que era, cal considerar com el meu primer record fals. Mirava com rentava una criatura nua; no en recordo el sexe, però observava en una de les seves natges una horrible massa pul.lulant de formigues que semblava estacionada en un forat de la mida de una taronja. Enmig de les ablucions, van girar la criatura posant-la de panxa enlaire, $i$ aleshores vaig pensar que les formigues serien esclafades i que el forat li faria mal. La criatura fou novament posada en la seva posició original. La meva curiositat per veure una altra vegada les formigues era enorme, però vaig comprovar amb sorpresa que ja no hi eren i que tampoc no hi havia cap rastre del forat. Aquest record fals és molt clar, encara que no puc pas localitzar en el temps. DALí, Salvador, 1981, p. 40.

32 DALí, Salvador, 2008.

33 Se hacen presentes las ruinas griegas y romanas a través de la referencia a medallas de bronce con inscripciones, figuraciones, batallas, etc.

34 Dalí, en su diario de 1919-1920, remarca en distintas ocasiones la presencia de campesinos venidos de fuera en la Rambla A modo de ejemplo, podemos leer: A l'anar a estudi he trobat la Rambla gran multitud de gent que, estacionada en grups, mirava enlaire. Tothom estava bocabadat, $i$ com més anava, més gent s'hi afegia. Tots el pagesos vinguts de fora, tothom allí mirava enlaire instintivament. DALÍ, Salvador, 1994, p. 65.
} 
en el poema horror ni terror, sino angustia. ${ }^{35}$ Conviene remarcar este hecho, pues en el transcurso de 1929-1930 Dalí pasó uno de los periodos más angustiosos de su vida: el poder opresor omnipresente de su padre, una época de risas incontrolables e histéricas cercanas a una delicada salud mental, un deseo sexual irreprimible pero a su vez inalcanzable por un terror mayor que el deseo de contacto físico y el posterior alejamiento de la locura. Esta era la situación de Dalí en el momento de crear estas obras y dicho poema, antesala o primeras luces del método paranoico-crítico. Son puntos a tener en cuenta a la hora de desligar la langosta de un significado asociable al terror y a la fobia del pintor: es símbolo de angustia, y si su fuente es, como pretendo, la falsa gárgola de la Casa Roger, podría incluso vincularse dicha imagen desde la casa paterna con su padre, causa primaria de la angustia del pintor.

Más adelante, el poema comienza un listado de fuentes que asemejan animales podridos, siendo los que más se repiten los saltamontes, un total de ocho veces. Se hace referencia cuatro veces a saltamontes podridos, dos a angustiosos saltamontes podridos y por último en dos ocasiones a una especie de pez cuya cabeza tiene un parecido angustioso con la de un saltamontes. Solo en esta ocasión podemos reconocer en el poema la relación entre el saltamontes/langosta y su trauma infantil, curiosamente el único animal que no se menciona en estado de putrefacción. Así mismo, la palabra angustioso solo aparece con relación al saltamontes. Hacia el final del poema aparece la idea del "aparentemente falso saltamontes", compuesto por infinidad de fotografías de tiburones. La relación directa del poema con sus vivencias de 1929 se confirma al final del poema, cuando el yo poético regresa con el conductor de un bote a recoger a una playa distinta porque los "dos jóvenes que no conocían en modo alguno la región habían querido ir a pie a la playa vecina". ${ }^{36}$ Es una referencia clara a las visitas que recibió Dalí en el verano de 1929.

Desgranadas todas estas fuentes iconográficas presentes en sus pinturas así como en el poema, resulta llamativo el empeño obcecado de Dalí por no mencionar los referentes reales de sus cuadros de 1929, pero también es cierto que no resulta extraño. Dalí dio a estas creaciones un cariz casi alucinatorio, asegurando que eran las pinturas más netamente surrealistas jamás realizadas hasta el momento, convirtiéndose él en un intermediario entre la visión totalmente liberada del "yo" consciente y su plasmación figurativa. ${ }^{37}$ Dalí, en su Vida secreta, habla de este periodo en términos que remarcan su supremacía intelectual dentro del grupo surrealista, y cómo esta era aceptada y admirada por dicho grupo, en el cual, realmente, estaba tratando de entrar. ${ }^{38}$ Ello lo consiguió con estas pinturas pretendidamente fruto de su sub-

35 En tanto que la membrana que cubre / enteramente su boca / se endurece a lo largo de la angustia del / del enorme saltamontes / agarrado inmóvil y pegado contra ella / tras cinco días y cinco noches. DALÍ, Salvador, 2008.

36 DALí, Salvador, 2008

37 "Me disponía a entrar en el grupo surrealista, cuyos temas y consignas acababa de estudiar concienzudamente, desmenuzándolas hasta llegar al último huesecillo. Me imaginaba que se trataba de trasladar el pensamiento al lienzo de forma espontánea, sin el menor escrúpulo racional, estético o moral". DALÍ, Salvador, 2010, p. 28. En este sentido, es de remarcar que la primera vez que Dalí describió su fobia fue en un texto publicado el 3 de marzo de 1929, L'alliberament dels dits, en la revista L'Amic de les Arts, defendiendo en dicho texto un arte que sea "un vagar sin método por los caminos de lo involuntario y constatar los hechos que cada día y de forma violenta cobran significado y que nos guían a su razón esencial, tal como indica Bretón: "QUI ME SERAIT PROPE ET NE ME SERAIT PAS DONNÉE". DALÍ, Salvador. La liberación de los dedos, 1929 en BUCKLEY, Ramón; CRISPIN, John, 1973, p. 350. El pintor, que cita a Breton y no por casualidad, dará en el texto una justificación surrealista al insecto justamente en el momento en que comienza a aparecer en su obra, retrayendo el nacimiento de dicha fobia a los ocho años. Continúa el texto diciendo "Desde aquel día he sentido un verdadero horror a las langostas, horror que se repite con igual intensidad cada vez que mi vista se tropieza con ellas: su recuerdo me produce una angustia penosísima. Cabe anotar aún que la anécdota del pez se me borró totalmente de la memoria hasta que mi padre me la recordó, y entonces la reviví con claridad inusitada". DALÍ, Salvador, 1929. En BUCKLEY, Ramón; CRISPIN, John, 1973, p. 351. Parece increíble que un recuerdo de infancia le marcase tanto y que, por otra parte, jamás mencionase la existencia de la escultura en forma de langosta de enfrente de su casa. Es más probable que se tratase de una omisión premeditada, al igual que de forma premeditada no habla en sus textos autobiográficos sobre El Bosco, por más que su hermana nos confirma su pasión por él (Véase la nota 21).

38 Pueden entenderse como pruebas de ello el distanciamiento con su padre, pues no quiso retractarse de la obra que les enemistó, seguramente por miedo a ser excluido del grupo surrealista. Así mismo, Dalí negó a George Bataille el permiso de reproducir El juego lúgubre en su artículo que publicó en 1929 sobre el cuadro (mostrando Bataille, en vez de una reproducción del cuadro, un dibujo hecho por él mismo); esta negación puede entenderse fruto del deseo expreso de Dalí por no molestar a Breton y asegurarse así su acceso al grupo, pues Breton y Bataille estaban enfrentados. Además, Dalí era consciente que el carácter escatológico de su pintura no era del agrado de Breton. Sobre los segundos aspectos véase: ARMENGOL, Laia Rosa, 2003, pp. 406-407. 
consciente liberado, algo que defenderá después en los postulados de la teoría del método paranoico-crítico. Sin embargo, estas obras, descubierto el origen de los elementos en ellas representados, muestran que no se trataría de pinturas subconscientes, sino plasmaciones conscientes de cómo debería ser una pintura hecha por el subconsciente. Dalí, preso del deseo de protagonismo entre los artistas surrealistas, pretendió ocultar los referentes que él unía deliberadamente de forma delirante y ocultó su origen racional, mostrando sus pinturas como netamente subconscientes.

Solo un detalle queda por exponer: en este grupo de pinturas aparecen una serie de ideas e iconos que se repiten a lo largo de la obra de Dalí hasta el fin de sus días: la sexualidad, la abyección, el tipo de paisaje influido por de Chirico, las caras blandas, las hormigas, las caracolas marinas... incluso en una fecha tan tardía como 1982 vemos resurgir la estructura de El enigma del deseo-mi madre, mi madre, mi madre en Composición - Patio del Escorial con Figura y Sebastián De Morra, Enano de Velázquez (1982, sin ubicación).

Sin embargo, el pintor desechó el empleo de la gran langosta de su repertorio, por más que fue un elemento de gran trascendencia durante 1929, reapareciendo tan solo en La fuente (1930, The Salvador Dalí Museum, St. Petersburgo [Florida]) y en Primer retrato de Gala (1931, Albert Field Collection, New York).

Sinceramente, no soy capaz de dar una razón a este hecho. Resulta romántico pensar que esta desaparición casi absoluta de la gran langosta en sus pinturas se deba al distanciamiento de su padre, al imaginar que el significado real del insecto tiene su reminiscencia en su calle natal y las vistas desde la Casa Puig y la Casa Mas Roger. De ser así, la langosta no sería símbolo del terror, sino de la infancia del pintor. Sin embargo, esta explicación sentimental pierde fuerza al constatar por fotografías que en las paredes de su apartamento de París colgaba El Gran Masturbador en 1932. ${ }^{39}$ En cualquier caso, el origen iconográfico de dicho insecto no debe- mos buscarlo en sus oscuros traumas infantiles, sino en la clara escultura ubicada frente a su casa natal.

\section{Bibliografía*}

ARMENGOL, Laia Rosa. Dalí, icono y personaje. España: Catedra (Ensayos Arte), 2003

BUCKLEY, Ramón; CRISPIN, John. Los vanguardistas españoles. Madrid: Alianza Editorial, 1973.

COSTA, Cuca R. (coor.). Dalí and his studios (Castillo de Gala Dalí, Púbol, 2013). Figueres, Girona: Ed. D.A.S Edicions, 2013.

DALÍ, Ana María. Salvador Dalí visto por su hermana. Pallars, Barcelona: Parasifol Ediciones, 2001.

DALÍ, Salvador. A Dalí journal 1920 / Impresions and private memoris of Salvador Dalí, January 1920. Cleveland (Ohio): Privately printed by Stratford press in limited edition for The Reynolds Morse Fundation, 1962.

DALÍ, Salvador. Vida secreta de Salvador Dalí. Esplugues de Llobregat, Barcelona: DASA EDICIONS, 1981.

DALÍ, Salvador. Un diari: 1919-1920. Les meves impresions i records íntims. Barcelona: Edicions 62, 1994.

DALÍ, Salvador. Tardes d'estiu. Barcelona: Edición especial de 600 ejemplares para la revista Cave Canis, 1996.

DALÍ, Salvador. El Gran Masturbador. España: Ayuntamiento de Málaga (Colección El violín de Ingres), 2008.

DALÍ, Salvador. Diario de un genio. España: Tusquets Editores, 2010.

DALÍ, Salvador; PARIANUD, André. Confesiones inconfesables. Barcelona: Editorial Bruguera, 1975.

DALÍ, Salvador; PARINAUD, André. The Unspeakable Confessions of Salvador Dalí. New York: Ed William Morrow, 1976

FANÉS, Fèlix. El Gran Masturbador. Madrid: Electa, 2000.

FANÉS, Fèlix. La pintura y sus sombras. Cuatro estudios sobre Salvador Dalí. España: Museo de Teruel, 2004.

FANÉS, Fèlix. Salvador Dalí. The construction of the image 1925-1930. Singapur: Yale University Press-New Haven and London, 2006.

GAILLEMIN, Jean-Louis. Salvador Dalí. Désirs inassouvis du purisme au surréalisme 1925-1935. Francia: Le Passage, 2002

GIBSON, Ian. La vida excesiva de Salvador Dalí. Barcelona: Editorial Empúries, 1998.

MINGOT BATLLOR, Joan M. (ed.) Salvador Dalí -Lletres i ninots- Fons Dalí del Museu Abelló. España: Museu Abellò, 2001

RODRIGO, Antonia. Ana María Dalí y Salvador (Escenas de infancia y juventud). España: Editorial Base, 2008.

ROIG, Sebastià; PUIG, Jordi. Dalí. El triángulo de I'Empordà. Barcelona: Triangle Postals S.L., 2003.

VÁZQUEZ DUEÑAS, Elena. El Bosco en las fuentes españolas. España: Ediciones Doce Calles, 2016.

VEHI, Pere (dir.). Del primer Dalí al Manifest Groc. Museu de Cadaqués, 2 de julio de 2011-15 de octubre de 2011. Sant Joan de les Fonts, Girona: Ed. Museu de Cadaqués, 2011.

\footnotetext{
${ }^{39}$ A pesar de esta apreciación, Fèlix Fanés cree posible una relación entre la langosta y el padre de Dalí: “Es muy probable que ese insecto simbolice algún tipo de amenaza representada por su padre. En este sentido no podemos dejar de mencionar lo que el pintor explicó en 1939 a un periodista de The New York Times: 'Cuando era un niño en Cataluña me gustaba salir al campo y pararme a descansar bajo el sol mientras soñaba. Pero había algo que solía estropear esos paseos: la gran cantidad de langostas que saltaban sobre mí. Las odiaba y las temía porque frustraban mi placer. Mi padre también me frustraba en muchos de mis deseos. Era un notario muy estricto y lleno de viejas ideas que no deseaba que su hijo se convirtiera en un artista. A medida que yo iba creciendo, mi padre me resultaba cada vez más antipático y en mi cabeza substituía su imagen por la de una langosta'". FANÉS, Fèlix, 2000, p. 42.

* Deseo mostrar mi agradecimiento a la Fundación Gala-Salvador Dalí de Figueres por su buena recepción, y a los miembros de la Oficina de Turisme de Figueres que tan amablemente resolvieron algunas dudas a lo largo de este estudio.
} 
